\title{
Static model of oil viscosity reduction for automatic pulse current exposure regulation system
}

\author{
V.A. Sasarov ${ }^{1}, A . V$. Yudin $^{1}$, and M. A. Fedorova ${ }^{2}$ \\ ${ }^{1}$ Department of Electric Power And Industrial Electronics, FSBEI HE Rybinsk State Aviation \\ Technical University (RSATU), Rybinsk, Russia \\ ${ }^{2}$ Department of Aviation Engine,FSBEI HE Rybinsk State Aviation Technical University (RSATU), \\ Rybinsk, Russia
}

\begin{abstract}
The article considers an open automatic control system (ACS) with compensation based on a model of the viscosity reduction process. The model is implemented in the MATLAB system and takes into account the initial kinematic viscosity of the oil, its temperature, and density. Modeling of each block of the proposed ACS is performed. An example of the functioning of the ACS to compensate for temperature effect is considered.
\end{abstract}

\section{Introduction}

Proven oil reserves in Russia are up to 14 billion tons, which account for $6 \%$ of the world's total. In 2019, oil production in Russia amounted to approximately 561,2 million tons. All oil fields are geographically separated and have transportation lines of thousands of kilometers.

Oil extraction and transportation take place in severe temperature conditions. For instance, in the Nenets Autonomous District, where oil fields have been discovered, the temperature may drop to $-47.4^{\circ} \mathrm{C}$ in the cold season. [1]. Such a significant decrease in ambient temperature affects the speed of oil transportation and leads to stricter requirements for pumping equipment, which results in extra economic costs for oil transportation.

Nowadays, one of the main methods for oil viscosity reduction is thermal heating. It is implemented in different ways: production of heat by burning hydrocarbon-containing substances (coal, oil, gas) in boilers; transfer of heat generated during the operation of pumps; electrical heating of the pipeline. [2].

This method is characterized by relatively low efficiency and highenergy consumption. In order to achieve effective viscosity reduction, it is necessary to break the chemical bonds of the oil. A prospective technology of oil processing, which consists of the exposure of oil to pulse current for decreasing its viscosity, has been developed for that purpose. Such a process and a device for the reduction of high viscosity of petroleum products are described in the patent [3]. 


\section{Researches}

In order to continuously record values of the initial parameters of oil and external parameters that affect its viscosity, it is necessary to automate this process while preparing oil for transportation.

If we consider the automation of the oil and gas industry as a whole, then first of all we should highlight the control systems of the processes of reception, processing and transportation of petroleum products, which are intended to improve the reliability and efficiency of operations [4].

According to [5], the implementation of an automatic regulation system significantly increases the overall economic performance of the technological chain. When analyzing the results, it becomes obvious that automation reduces equipment downtime, increases labor productivity, improves working conditions of the personnel, and saves resources. Concerning oil and gas industry enterprises, where the likelihood of technological accidents is rather high, automation also minimizes the risks of such disasters.

In [6], a system analysis of the use ocomplex objects using fuzzy logic in temperature profile administration systems for transportation of viscous, high-viscosity and high-sulfur oil, which allows to improve the operating modes of pumping equipment, is presented.

The article [7] raises the issue of the process of transportation oil and oil-water mixture at the sites, of oil production, transportation, and refining at lower temperatures. A type of cavitational vortex heat generator, which has significant advantages over regular heaters when completed with a controlling automation system, is proposed.

The article [8] deals with automation of the petroleum products transportation process which consists in constant monitoring of fluid pressure in pipeline sections during the operation of the pumping station.

Electric current is applied to effectively handle oil as a means of reducing its viscosity.

Studies on the electric current impact on oil are conducted all over the world. Methods of splitting using high-frequency and high-voltage impulse DC electric fields are widely applied in the oil industry, where the occurrence of water-in-oil dispersions is extremely undesirable because of physical limitations and high maintenance costs which are required for elimination of such dispersions [9]. In this article the results of research of applied electric field parameters' impact on the formation of water chains in oil-water emulsions are presented.

In the article [10], an issue of complexity of pretreatment of low-quality crude oil by electric demineralization is raised. And a process of developing of technology for deemulsification of the electric field of crude oil emulsion is presented.

In the study [11], the effect of electric current high-frequency impulses for the coalescence of water drops in oil-water emulsions is considered. An analysis through research of impacts depending on the amplitude of an impulse, frequency of impulses, and the width of an impulse has been conducted.

Having analyzed the above, we can conclude that the automation of the process of reducing oil viscosity is an urgent task, the implementation of which will lead to a significant decrease in economic costs of transportation.

In order to record values of input parameters of oil and external parameters that affect its viscosity, it is necessary to integrate an automatic control system (ACS) into the unit to reduce oil viscosity by current pulses.

The ACS allows to automatically administering capacity and frequency of current pulses depending on all characteristics which affect oil viscosity, and also regulate the gap between the electrodes as they wear out. 
An ACS can be of one of three types: open, closed, and combined. Let us apply the open ACS as the first solution. This is due to the complexity of the configuration of a closed ACS in the absence of a model of the viscosity reduction process, which most likely appears to be a non-linear ACS.

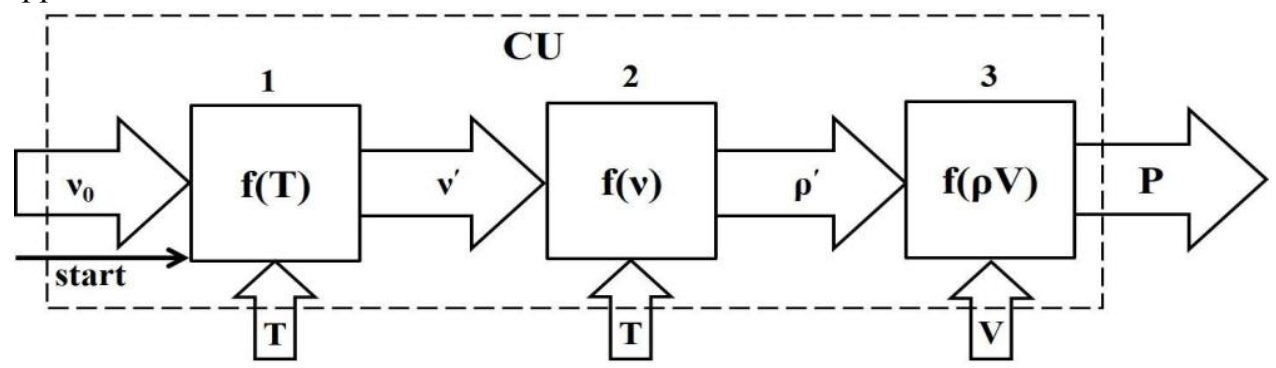

Fig. 1. The structure of the open ACS for viscosity reduction.

$\mathrm{CU}$ is the control device includes 3 blocks. 1 block is the dependence of viscosity on temperature: $v 0$ is the initial kinematic viscosity of the oil at the time of the system launch $(\mathrm{m} 2 / \mathrm{sec}), \mathrm{T}$ is the oil temperature $(\mathrm{K}), v^{\prime}$ is the viscosity based on the temperature $(\mathrm{m} 2 / \mathrm{sec})$; 2 block is the transition from viscosity to density: $v^{\wedge}$ is the desired oil viscosity $(\mathrm{m} 2 / \mathrm{sec}), \rho$ is the oil density $(\mathrm{kg} / \mathrm{m} 3) ; 3$ block is the dependence of capacity on density: $\mathrm{V}$ is the productivity of the facility $(\mathrm{m} 3 / \mathrm{sec}), \mathrm{P}$ is the capacity needed to reduce the oil viscosity to the required value $(\mathrm{kW})[12]$.

A static model of oil viscosity reduction

In order to implement an open ACS, familiarity with an at least approximate model of the process is required. We can develop a static model of oil viscosity reduction based on several experimental points [13].

Temperature dependence of viscosity

To create the model, we can use Walter's empirical formula for the temperature dependence of viscosity, which describes the dependence of kinematic viscosity of oil on temperature (1):

$$
\log \log (\log \log (v+c))=a+b * \log \log T .
$$

The formula includes $\mathrm{T}$ - temperature of oil $\mathrm{K}, v-$ kinematic viscosity at a given temperature and three constants - a, b and c, which depend on the nature of the researched liquid.

These three constants can be quantified if we know the three experimental points for the product, i. e.,the values of viscosity for any three temperatures. By entering these values into the formula, we obtain three equations with three unknown variables, the solution of which will allow us to determine these three constants.

In order to perform calculations, we can simplify the Walter formula to allow its application on the basis of two experimental points. At the same time, we will keep in mind that the constant "c" in equation (1), if the viscosity is expressed in centistokes, has the maximum value of 1.3 (for gasoline) and the minimal value of about 0.5 (for some highviscosity petroleum products). Based on the above, for all petroleum products (oils, lubricants) with viscosity exceeding $2-5 \mathrm{cSt}$, the average value of $\mathrm{c}=0.8$ is applicable in formula (1).

The simplified Walter's formula looks like this:

$$
\log \log (\log \log (v+0.8))=a+b * \log \log T
$$

At low viscosity, formula (2) isnot suitable as at $\mathrm{v} \leq 0.2 \mathrm{cSt}$ and the equation becomes completely meaningless 
Let us utilize the MATLAB package of applications for solving problems in technical calculations to determine parameters of the dependence of kinematic viscosity of oil on the temperature model.

Letus apply the Curve Fitting Tool package for the approximation of the simplified Walter's formula (2). The package provides a special tool for performing interactive approximation. This instrument does not work with implicit functions, i.e., complex transformations of the initial formula (2) are required to express viscosity in the left part of the equation.

As an alternative, an analytical solution of a system of logarithmic equations with two unknown variables, "a" and "b", can be applied for the approximation of Walter's formula (2).

To conduct an analytical solution, let us use the reference book Oils of the North Caucasus. Table 1 demonstrates changing of the oil viscosity depending on the experimentally acquired temperature [14].

Table 1. Changes of the oil viscosity depending on the temperature.

\begin{tabular}{l|l|l|l|l|l}
\hline $\mathrm{t},{ }^{0} \mathrm{C}$ & 0 & 5 & 10 & 20 & 30 \\
\hline $\mathrm{T}, \mathrm{K}$ & 273 & 278 & 283 & 293 & 303 \\
\hline$v, \mathrm{cSt}$ & 29.4 & 24 & 20.6 & 14.4 & 9.5 \\
\hline
\end{tabular}

Letus divide expression (2) into 2 components to perform an approximation of the analytical solution to simplify the calculations and visualization of the results. So let usintroduce additional variables into the MATLAB:

$$
\begin{gathered}
\quad R E=\log \log (\log \log (v+0.8))-\text { the left part of expression }(2) ; \\
=a+b * \log \log T-\text { the right part of expression }(2)
\end{gathered}
$$

As a result of the analytical solution of the system of equations, the coefficients have been determined: $a=8.48456$ and $b=-3.4099926$.

The approximation result is characterized by a low level of accuracy. To specify the values of $a$ and $b$, let $u$ apply the analytical matching method. In this case, the desired coefficients have the following values: $a=8.48456$ and $b=-3.4115$.

This result is better but such approximation is rather complex, inconvenient, and demonstrates low accuracy. The approximation suitability criterion, i.e., the root of the average for the squared RSME flaw, is almost equal to 2 . That is why it was decided to give up formula (2) with logarithms.

A good result is obtained through the approximation of the function with the use of the Curve Fitting Tool package in the form of a rational expression

$$
f(x)=\left(p_{1} * x^{2}+p_{2} * x+p_{3}\right) /\left(x+q_{1}\right)
$$

To perform the approximation, let's take the set of data from Table 1 .

In our case, we will choose a quadratic polynomial and a linear polynomial.

To evaluate the quality of the approximation, a series of numerical criteria have been analyzed which are calculated automatically in the cftool application.

The SSE approximation suitability criterion is the sum of squares of errors.In our case $S S E$ is equal 0.07345 . The proximity of the SSE to zero shows the good quality of approximation of data by the parametric model.

The R-square criterion is the square of mixed correlation. He is determined as the ratio of the sum of squares related to the SSR regression to the total sum of squares (SST).

The R-square criterion can take values only from 0 to 1 , and the closer it is to 1 , the better approximation of input data is achieved by the parametric model. In this case, the Rsquare criterion is 0.9997 . 
Its value cannot exceed 1 , and the values of the adjusted R-square close to 1 illustrate the good approximation of input data by the parametric model. The adjusted R-square criterion Adjusted R-square is 0.9988 .

The square root of the average for the RSME (Root mean Squared Error)is equal0.271. The values of the RSME close to zero represent a good approximation of input data by the parametric model.

On the basis of the analysis of the suitability criteria, we can conclude that the approximation of the function in the form of rational expression (5) is optimal if compared with the classical Walter's formula (2) for its application to the creation of the dependence of kinematic viscosity of oil on temperature model.

Detailed information, as well as additional drawings, can be found in the article [15].

The transition from viscosity to density

Let us develop a model of the second block of the transition from oil viscosity to density (Fig. 1). This requires modeling of the dependence of density of the researched oil sample on temperature. Let us apply the formula

$$
\rho(\mathrm{T})=\rho_{20} *[1+\zeta *(20-T)]
$$

where $\rho 20$ is the density of oil at $20^{\circ} \mathrm{C}$; $\zeta$ is the cubic expansion coefficient (Table 2).

Table 2. The values of the cubic expansion coefficient [16].

\begin{tabular}{l|l|l|l}
\hline$\rho, \mathrm{kg} / \mathrm{m}^{3}$ & $\zeta, 1 /{ }^{\circ} \mathrm{C}$ & $\rho, \mathrm{kg} / \mathrm{m}^{3}$ & $\zeta, 1 /{ }^{\circ} \mathrm{C}$ \\
\hline $800-819$ & 0.000937 & $900-919$ & 0.000693 \\
\hline $820-839$ & 0.000882 & $920-939$ & 0.000650 \\
\hline $840-859$ & 0.000831 & $940-959$ & 0.000607 \\
\hline $860-879$ & 0.000782 & $960-979$ & 0.000568 \\
\hline $880-899$ & 0.000738 & $980-999$ & 0.000527 \\
\hline
\end{tabular}

The dependence of the power from density

In order to model the third block (Fig. 1), namely, to determine the capacity which is necessary for oil viscosity reduction, a mathematical model of intermolecular bonds was developed.

The relative energy of $\mathrm{C}-\mathrm{C}$ and $\mathrm{C}-\mathrm{H}$ bonds for the considered oil $(100 \%)$ are:

$$
E_{u d}=\frac{E_{C-C}}{M_{\mathrm{H}}}+\frac{E_{C-H}}{M_{\mathrm{H}}}(\mathrm{kJ} / \mathrm{kg}),
$$

where $\mathrm{E}_{\mathrm{C}-\mathrm{C}}$ is the relative energy of bonds $\mathrm{C}-\mathrm{C}$ of the considered oil $(\mathrm{kJ} / \mathrm{mol})$; $\mathrm{EC}-\mathrm{H}$ is the relative energy of bonds $\mathrm{C}-\mathrm{H}$ of the considered oil $(\mathrm{kJ} / \mathrm{mol}) ; \mathrm{MH}$ is the molar mass of the considered oil $(\mathrm{kg} / \mathrm{mol})$.

The energy $\mathrm{E}$ which is required to break intermolecular bonds under the defined capacity of the facility:

$$
E=E_{u d} * V * \rho^{\prime}(\mathrm{kJ} / \mathrm{sec})
$$

where $\mathrm{V}$ is the productivity of the unit $(\mathrm{m} 3 / \mathrm{sec}) ; \rho^{\prime}$ is the density of the researched oil with consideration of the temperature $(\mathrm{m} 2 / \mathrm{sec})$.

It is necessary to add $\mathrm{K}_{\mathrm{E}}$ - the percentages of broken bonds (\%) - to the final version of the formula. It defines the proportion of the bonds that should be broken to achieve the given viscosity. It must be determined before the launch of the system.

$$
P=E_{u d} * V * \rho^{\prime} * K_{E}(\mathrm{~kW})
$$

The flow of oil must be exposed to that particular amount of capacity from the source of impulses in order to reduce viscosity to the value determined earlier.

Realization of the open-loop control principle 
Let us review an example of the functioning of the automatic regulation system with compensation. Let us consider an oil with the following range of input data with the temperature of the oil set at $20^{\circ} \mathrm{C}$ (Table 3).

Table 3. The range of the input data for the calculation.

\begin{tabular}{|c|c|c|c|c|c|c|c|c|c|}
\hline $\begin{array}{l}\mathrm{t}_{0}, \\
{ }^{0} \mathrm{C}\end{array}$ & $\begin{array}{l}\mathrm{T}_{0} \\
\mathrm{~K}\end{array}$ & $\begin{array}{l}\mathrm{E}_{0}, \\
\mathrm{kj}\end{array}$ & $\begin{array}{l}v_{0} \\
\mathrm{~m}^{2} / \mathrm{sec}\end{array}$ & $\begin{array}{l}\mathrm{P}_{0}, \\
\mathrm{~kW}\end{array}$ & $\begin{array}{l}\mathrm{V}, \\
\mathrm{m}^{3} / \mathrm{sec}\end{array}$ & $\begin{array}{l}\rho_{0}, \\
\mathrm{~kg} / \mathrm{m}^{3}\end{array}$ & $\begin{array}{l}\mathrm{E}_{\mathrm{C}-\mathrm{C}}, \\
\mathrm{kJ} / \mathrm{mol}\end{array}$ & $\begin{array}{l}\mathrm{E}_{\mathrm{C}-\mathrm{H}}, \\
\mathrm{kJ} / \mathrm{mol}\end{array}$ & $\begin{array}{l}\mathrm{M}_{\mathrm{H}}, \\
\mathrm{kg} / \mathrm{mol}\end{array}$ \\
\hline 20 & 293 & 0 & $14.4 * 10^{-6}$ & 0 & 0.0005 & 867 & 307 & 394 & 0.38 \\
\hline
\end{tabular}

Because of the lack of dependence of oil viscosity reduction on the number of broken bonds (in percentage), we can assume $\mathrm{K}_{\mathrm{E}}=100$ (\%).

Let us consider that the initial viscosity is optimal and the regulation system should sustain the viscosity $v^{\wedge}=14.4 * 10^{-6} \mathrm{~m}^{2} / \mathrm{sec}$. The oil temperature changes and becomes equal to $t=12^{0} \mathrm{C}(T=285 \mathrm{~K})$. The regulation system responds to the temperature change. On the basis of the established temperature, a new value of the viscosity is determined (Fig. 2): $v^{\prime}=19 * 10^{-6} \mathrm{~m}^{2} / \mathrm{sec}$.

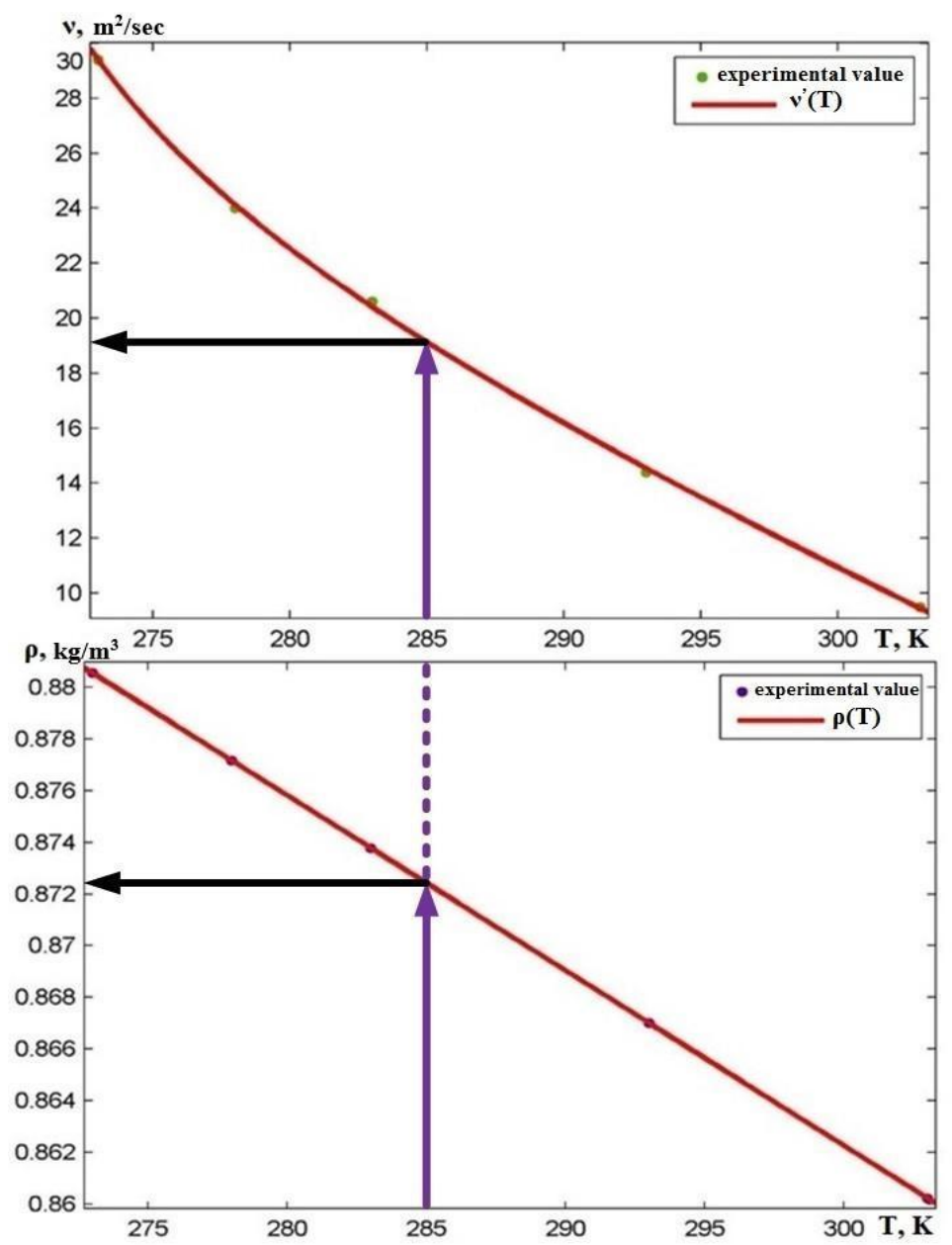

Fig. 2. Graphic illustration of the functioning of the ACS with compensation. 
A transition from the new value of viscosity to the new value of density $\rho^{\wedge \prime}=872.4$ $\mathrm{kg} / \mathrm{m} 3$ takes place. The capacity $\mathrm{P}$ is calculated using the new value of density.

$E_{u d}=1844.74(\mathrm{~kJ} / \mathrm{kg})$;

$E=804.7(\mathrm{~kJ} / \mathrm{sec})$

$P=804.7 * 100 \%=804.7(\mathrm{~kW})$ :the flow of oil must be exposed to that particular amount of capacity from the source of impulses in order to reduce viscosity to the value determined earlier.

\section{Conclusion}

As a result of the study, a model for oil viscosity reduction has been developed: a twodimensional phase administration environment. The model allows retrieving the energy value of impulses, which is needed for viscosity reduction by a specified amount given the influence of temperature. The model developed can serve as a basis for modeling the oil viscosity reduction process with various initial parameters. Extra required values, which affect the viscosity of the oil, can be also added to it.

The model developed is suitable for functioning as a part of an automatic control system. It is planned to additionally enhance the ACS for oil viscosity reduction with current pulses by adding to it a system for controlling the interelectrode gap, and it will also take into account the pressure in the pipeline. It is intended to move from the open model of oil viscosity reduction with compensation to the closed one. The dynamics of the process should be additionally studied for this purpose.

\section{References}

1. Weather and climate, On-line monitoring of weather and climate on a global scale. Electronic resource: http://www.pogodaiklimat.ru/climate/23205.htm (date accessed: 29.11.2020).

2. B.N. Abramovich, P.A. Kuznetsov, Yu.A. Sychev, Protective Controller against Cascade Outages with Selective Harmonic Compensation Function. Journal of Physics: Conference Series, 1015(2), 022001 (2018)

3. Lazarus Saidakovsky, Sergey Rakhinskiy, Nicolai Novikov. Treatment process and apparatus for reducing high viscosity in petroleum products, derivatives, and hydrocarbon emulsions, and the like.(United States Patent Application Publication Pub. No.: US 2014/0130400, May 15, 2014).

4. S.A. Koleda, Digital models as part of the fuel and energy complex digitalization. Business magazine NEFTEGAZ.RU,6 (102), 38-40(2020).

5. I. Salmanov, Overview of Automation Solutions in the Oil and Gas Industry. Automation and IT in the oil and gas industry,2 (28), 11-14(2017).

6. T.V. Tabachnikova, K.L. Gorshkova, Some Aspects of Automation of Temperature Regime of Primary Treatment and Transportation of Oil Streams. Monograph (Moscow: KnoRus Company, 2018)

7. M.G.Kovrizhkin, R.V.Arslanov, YU.N. Romanov, Automation system for oil line heaters based on a cavitation vortex generator. Automation, telemechanization and communication in the oil industry,. 4, 54-57(2011).

8. E.V. Alieva,E.G. Bochkova, S.S. Vasilev Automation of the process of transportation of petroleum products. Novainfo.ru.2 (50), 22-28(2016). 
9. LiaBin, SunZhiqian, WangZhenbo, JinYouhai, FanYuxin. Effects of high-frequency and high-voltage pulsed electric field parameters on water chain formation. Journal of Electrostatics,80,22-29 (2016).

10. J. Chen, S. Huang, J. Wang, J. Xi. Research of electrostatic demulsification technology under high-frequency/high-voltage pulsed AC electric field and its application in crude oil desalting. Petroleum Processing and Petrochemicals,5,12-19 (2017)

11. W. Kang, M. Li, H. Yang, X. Kang, F. Wang, H. Jiang, M. Zhang, T. Zhu, B. Sarsenbekuly, Coalescence behavior of aqueous drops in water-in-oil emulsions under high-frequency pulsed AC fields. Journal of Industrial and Engineering Chemistry, 93, 415-422 (2020).

12. V.A. Sasarov, M.A. Fedorova,E.A. Malofeev, Opened automatic regulation system to reduce oil viscosity. 15th all-Russian conference - competition of students and postgraduates of mining and geo-logical, oil and gas, energy, engineering and metallurgical profile, 290, (2019).

13. B.N. Abramovich,Y.A. Sychev,P.A. Kuznetsov,R.Yu. Zimin, Efficiency Estimation of Hybrid Electro technical Complex for Non-Sinusoidal Signals Level Correction in Autonomous Power Supply Systems for Oil Fields. IOP Conference Series: Earth and Environmental Science, 194(5), 052001 (2018).

14. E.S. Levchenko, E.N. Bobkova, E.A. Ponomareva Oil of The North Caucasus.(Moscow, Leningrad: Gostoptekhizdat, 1963)

15. V.A. Sasarov, A.V. Yudin, M.A. Fedorova Static model of viscosity for the method of electrohydrodynamic oil treatment. Bulletin of TSU. Technical science,4, 197205(2020).

16. N.A. Svarovskaya, Chemistry of oil and gas. Ed. Gubkin Russian state University of oil and gas. (I. M. Gubkin Department of organic chemistry and petroleum chemistry, Moscow, 2002). 